\title{
NATURAL SELECTION IN EXPERIMENTAL POPULATIONS OF TRIBOLIUM
}

\author{
II. FACTORS AFFECTING THE FITNESS OF THE MUTANT \\ "SPLIT" OF TRIBOLIUM CONFUSUM* \\ DANIEL J. MCDONALD and NANCY JANE PEER \\ Department of Biology, Dickinson College, Carlisle, Pennsylvanio
}

\section{INTRODUCTION}

Received 29.iii.6r

Several studies made in recent years have revealed a wide variety of means by which different traits may influence the fitness of an organism. Merrell and Underhill (1956), examining competition between mutant and wild type flies in experimental populations of Drosophila melanogaster, concluded that inequalities in the mating success of males strongly influenced the fitness of the various phenotypes. The fitness of karyotypes found in natural populations of Drosophila persimilis was shown by Spiess (1958) to depend upon differences in preadult viability and development rate. Using an organism other than Drosophila, McDonald and Peer (1960) found that in experimental populations of the flour beetle, Tribolium confusum, the decline in the frequency of a sex-linked lethal was due primarily to the effects of the lethal on viability and fertility of mutant males and the viability of heterozygous females. Without recourse to population experiments, other investigators have found adaptive differences in olfaction and migratory activity (Harland and Jackson, I958) and productivity (Spofford, I956) among various strains of Drosophila; and productivity has also been shown to differ between a mutant and a wild type strain of Tribolium castaneum (Phillips and McDonald, I958).

With the isolation of the mutation split $(s p)$ of Tribolium confusum, an opportunity arose for further exploration of the ways in which heritable differences between strains of Tribolium can influence fitness. This mutation depresses the reproductive capacity of the mutant strain, but precise measurements of this effect were never made (McDonald, I959). The results reported here indicate that in experimental populations the $s p$ gene is rapidly replaced by the wild type allele, and that the lower fitness of the mutant strain is due largely to the inviability, subfecundity, and impotence of the mutant females.

\section{METHODS}

The standard medium and environmental conditions generally employed for rearing Tribolium confusum were used throughout these experiments. The medium

* This investigation was supported by grant G-8888 from the National Science Foundation and grant $\mathrm{RG}_{5}{ }^{8}{ }_{3}\left(\mathrm{R}_{1}\right)$ from the National Institutes of Health, United States Public Health Service. 
is a mixture consisting of 95 per cent. fine whole wheat flour and 5 per cent. dried brewer's yeast. The experiments, which fall into three groups, were conducted at a temperature of $30^{\circ} \mathrm{C}$. and, with the exception of the copulation experiments, a relative humidity of approximately 6 o per cent.

In the first group of experiments, populations consisting of a mixture of mutant and wild type individuals were allowed to reproduce continuously in cages operationally similar to those used for Drosophila. The cages have been described elsewhere (McDonald and Peer, 1960), but briefly, they are stainless steel rectangular containers about $13 \mathrm{~cm}$. wide, $18.5 \mathrm{~cm}$. long, and $18 \mathrm{~cm}$. deep, fitted with two rows of removable compartments-eight altogether-each $4.5 \mathrm{~cm}$. wide, $6.5 \mathrm{~cm}$. long, and $3.3 \mathrm{~cm}$. deep. These are made of perforated aluminum sheeting, and since they fit closely together the beetles can move freely from one to another. Initially, 400 grams of medium was added to each cage which filled it to about the level of the compartment rims. The food supply was renewed by removing old compartments, usually one or two each week, and replacing them with new compartments containing fresh medium. The schedule maintained in these experiments allowed each compartment to be changed once every six weeks. The medium from the old compartment was passed through a fine sieve leaving behind the adults, pupae, and larger larvae which were counted and then returned to the cage.

The second group of experiments was concerned primarily with comparing productivity of mutant and wild type individuals. In these experiments, a pair of adults (male and female) were placed in a glass vial containing three grams of medium for five days while the female deposited eggs, and then transferred to a second and third vial for two additional five-day periods. If either or both members of the pair died during the fifteen days, this was recorded, as well as the total number of adult offspring produced by each pair. Frequent transfers were employed to minimise the loss of offspring through the cannibalism of the adults.

Finally, mating activity was examined by placing a pair of adults in a small Stendor dish with an inside diameter of about $3 \mathrm{~cm}$. and observing the beetles until copulation occurred. The bottom of each dish was just barely covered with medium and twenty-four dishes were observed simultaneously in a square constant temperature box about $25 \mathrm{~cm}$. on edge and $5 \mathrm{~cm}$. deep and covered with a sheet of clear lucite. The relative humidity ranged from 30 to 70 per cent. The female was placed in the dish first and the time elapsing between the introduction of the male and the first copulation was recorded. If copulation had not occurred by the end of forty minutes, the experiment was terminated. Since the beetles are negatively phototropic, the lighting arrangement could conceivably affect their mating activities. Therefore, in these experiments a constant source of illumination was provided by overhead fluorescent lamps, but the intensity was not measured. Finally, to eliminate the restricted activity which the insect experiences if it accidentally falls upon its back, such individuals were immediately righted.

\section{RESULTS}

(i) The populations

The mutation split, isolated from a wild type stock of $T$. confusum several years ago, was found to be an autosomal recessive with a high degree of penetrance. The split phenotype is variable, but all mutant individuals will have shortened elytra which fail to meet at the midline and expose the posterior third of the abdomen. The mutant development rate did not seem different from that of wild type, which is about twenty-eight days at $30^{\circ} \mathrm{C}$., but preadult viability was found to be slightly depressed. Further, cultures of the $s p$ mutant always contained an unusually large number of dead imagoes, and pair 
matings involving them were frequently found to be sterile (McDonald, 1959). These preliminary observations indicated, therefore, that selection against $s p$ ought to proceed rapidly and that the mutation might provide adequate material for analysing the factors determining selective values in Tribolium populations.

Two cages were started, each with an initial population of $462 s p$ adults and 4 wild type adults, equal numbers of each sex. The population cages showed so little activity at first that maintenance and sampling were not started until the tenth week. Then, each week

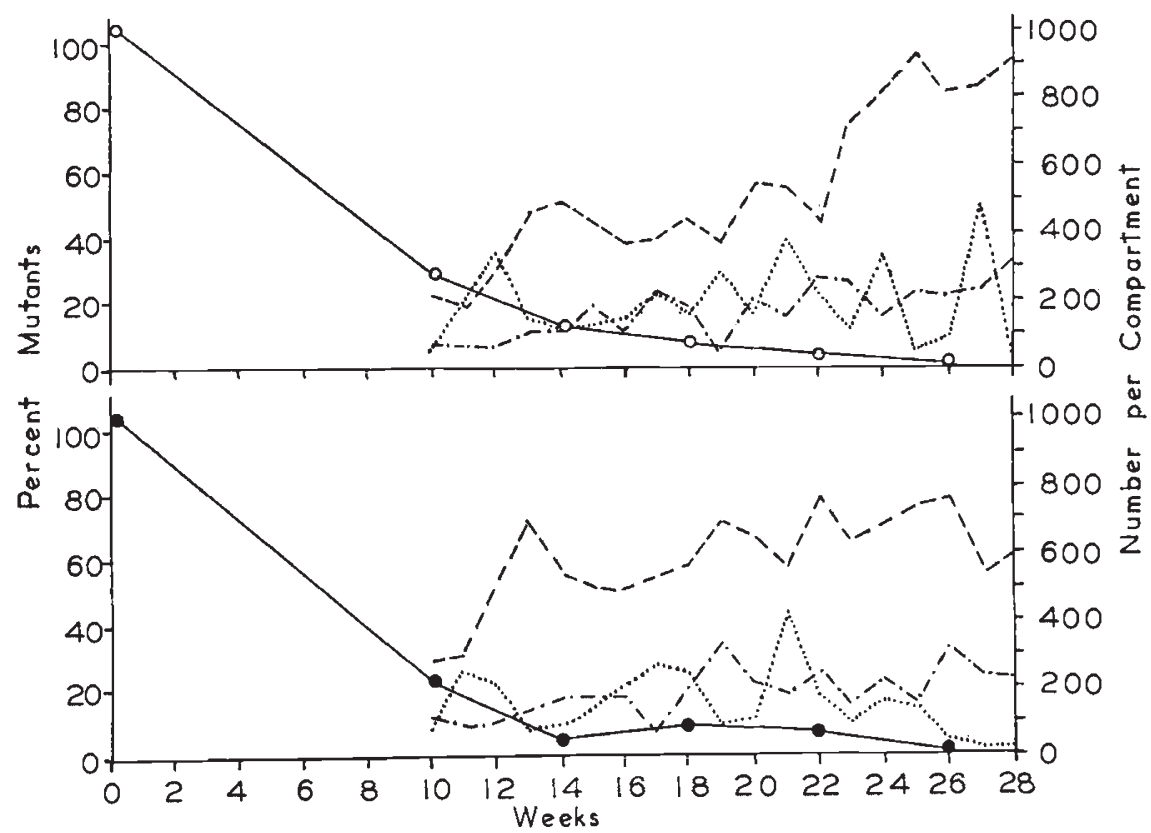

Fig. 1.-The numbers of live adults $(\ldots)$, dead adults $(\ldots)$, and pupae $(\ldots)$, and the percentage of live $s p$ mutant adults $(-)$ found in the weekly census samples from the two replicate population cages. Upper curves, Cage 21 ; lower curves, Cage 20.

the live adults, dead adults, and pupae found in the old compartment were counted, the dead adults discarded, and the living forms returned to the cage. Every fourth week a sample of 200 live adults was examined and the numbers of wild type and mutant individuals recorded. The high natality and mortality indicated by the numbers of pupae and dead imagoes found in the weekly census (fig. I) are signs of a population undergoing rapid turnover; and, since selection was operating, were accompanied by changes in genotypic frequencies. These changes show a gradual decline in the frequency of $s p$ homozygotes culminating in their elimination by the 26 th week. For this reason, the cages were discontinued two weeks later.

(ii) Productivity experiments

Adults two days old were used to make the following crosses: 
$s p / s p q \times+1+$ o, 149 pair matings; $+1+q \times s p / s p$ ô, I49 pairs; $+1+q \times+1+\delta, 94$ pairs; and $s p / s p+q \times s p / s p o$, 99 pairs. Several interesting facts emerge from the data collected and presented in tables I, 2, 3 and 4. Table I shows the productivity of each kind of mating in terms of the average number of adult offspring produced per pair. Obviously, there are marked differences among all the productivities. In general, the mutant females are far less productive than the wild type females regardless of their mate's phenotype but, in addition, there is the strong indication that each type of male is

TABLE I

Productivity of the four different crosses

\begin{tabular}{|c|c|c|c|c|}
\hline 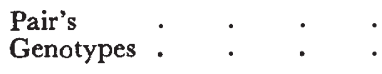 & $\begin{array}{l}s p / s p q \\
+1+\sigma\end{array}$ & $\begin{array}{l}s p / s p \text { ㅇ } \\
s p / s p \text { ot }\end{array}$ & $\begin{array}{l}+1+9 \\
+1+0\end{array}$ & $\begin{array}{l}+1+9 \\
s p / s p \\
0\end{array}$ \\
\hline Number of pairs . & I 49 & 99 & 94 & I 49 \\
\hline Total offspring & 553 & II 80 & $753^{8}$ & $744^{I}$ \\
\hline Offspring per pair & $3 \cdot 7$ & I $1 \cdot 9$ & $80 \cdot 2$ & $49 \cdot 9$ \\
\hline Number of fertile pairs & $\begin{array}{c}67 \\
\left(44^{\cdot} \cdot 9\right) *\end{array}$ & $(57 \cdot 5)$ & $\left(9^{91}\right.$ & $\begin{array}{c}127 \\
(85 \cdot 2)\end{array}$ \\
\hline Offspring per fertile pair & \multicolumn{2}{|c|}{$\begin{array}{l}8.2 \quad 20.7 \\
\text { test of significance } \\
t=4.0 \quad \mathrm{P}<0.00 \mathrm{I}\end{array}$} & \multicolumn{2}{|c|}{$\begin{array}{l}{ }^{82.8} \\
\text { test of significance } \\
t=8.7 \quad \mathrm{P}<0.001\end{array}$} \\
\hline $\begin{array}{l}\text { Offspring per fertile pair per } \\
\text { day }\end{array}$ & 0.55 & $1 \cdot 3^{8}$ & $5 \cdot 52$ & $3 \cdot 91$ \\
\hline
\end{tabular}

* Figures in parentheses are per cents.

relatively more productive with its own type of female. When mated with a wild type female, the productivity of $s p$ males is little more than half that of the wild type males, but with $s p$ female mates, the $s p$ males' productivity is about three times greater than that of the wild type males. The same pattern of productivity persists when only fertile pairs are considered, and the statistical tests show the productivity differences between the two kinds of males with each kind of female to be significant. Table 2 reveals that the death rate among $s p$ females is quite high during the first seventeen days of their adult life, for only 45.9 per cent. survive this length of time as compared to the $98 \cdot 8,97 \cdot 9$ and $99 \cdot 2$ per cent. surviving among the $s p$ male, wild type female, and wild type male groups, respectively. The difference in the proportion of living and dead among the four kinds of individuals at the end of the third period is highly significant (chi 
square $=4 \mathrm{II} \cdot \mathrm{I} ; \mathrm{P}<\mathrm{O} \cdot 00 \mathrm{I})$ with the $s p$ females making by far the greatest contribution to chi square. The individuals from the $s p / s p$ q $\times s p / s p$ ot crosses still living after the third five-day period were kept under observation for another thirty-five days. Death continued at a diminishing rate among the females for twenty-five days until only about 40 per cent. remained, whereupon no further deaths occurred. Only a few males died during this same period, so that survival never dropped below 98 per cent. Table 3 shows the number of fertile and infertile pair matings from each cross where both members of the pair lived for the entire fifteen-day period. Pairs in which either or both members had died before the end of fifteen days

TABLE 2

The number of adults surviving at the end of each five-day period

\begin{tabular}{|c|c|c|c|c|c|c|c|c|}
\hline \multirow{3}{*}{ Period } & \multicolumn{8}{|c|}{ Genotype } \\
\hline & \multicolumn{2}{|c|}{$s p / s p$ 우 } & \multicolumn{2}{|c|}{$s p / s p \sigma^{*}$} & \multicolumn{2}{|c|}{$+1+9$} & \multicolumn{2}{|c|}{$+1+a$} \\
\hline & No. & Per cent. & No. & Per cent. & No. & Per cent. & No. & Per cent. \\
\hline I & $2 \mathrm{II}$ & $85 \cdot I$ & 246 & $99^{\cdot 2}$ & $24 \mathrm{I}$ & $99 \cdot 2$ & $24 \mathrm{I}$ & $99 \cdot 2$ \\
\hline 2 & 140 & $5^{6} \cdot 4$ & 246 & $99^{\circ} 2$ & 240 & $98 \cdot 8$ & $24 \mathrm{I}$ & $99 \cdot 2$ \\
\hline 3 & II 4 & $45^{\circ} 9$ & 245 & $9^{8 \cdot 8}$ & $23^{8}$ & 97.9 & $24 \mathrm{I}$ & $99^{\circ} 2$ \\
\hline $\begin{array}{c}\text { Initial } \\
\text { number }\end{array}$ & \multicolumn{2}{|c|}{248} & \multicolumn{2}{|c|}{$24^{8}$} & \multicolumn{2}{|c|}{243} & \multicolumn{2}{|c|}{243} \\
\hline
\end{tabular}

were eliminated from consideration here, so that differences between the four kinds of crosses in the proportions of fertile and sterile pairs in each would not be influenced by viability. Upon comparing the mutant female matings with matings involving wild type females, these proportions were found to be significantly different (table 3), whereas no significant difference existed between crosses involving the two kinds of males. The results indicate a much greater frequency of sterility among $s p$ females than among wild type females. Finally, the data were analysed to determine if the productivity of the four crosses would be the same if only fertile and equally viable pairs were considered. This was done by selecting those pairs which were fertile the first period and lived through the entire fifteen days, and counting all the offspring produced by them during the last two fiveday periods. Only seven pairs (4.7 per cent.) of the $s p / s p q \times+1+\delta^{t}$ crosses and twenty-five $(25.2$ per cent.) of the crosses involving $s p / s p$ q $\times s p / s p$ ot met the above requirements as compared to 87.2 per cent. of the $+1+q x+1+\delta$ and 60.4 per cent. of the $+1+q \times$ $s p / s p$ t crosses. These data are given in table 4 along with the mean 


\section{TABLE 3}

The number of fertile and infertile pair matings where both members of the pair lived through the three periods

\begin{tabular}{|c|c|c|c|c|c|c|c|c|}
\hline \multirow{2}{*}{$\begin{array}{l}\text { Pair's } \\
\text { Genotypes }\end{array}$} & \multicolumn{2}{|c|}{$\begin{array}{l}s p / s p q \\
+1+\sigma\end{array}$} & \multicolumn{2}{|c|}{$\begin{array}{l}+1+q \\
+1+\sigma^{x}\end{array}$} & \multicolumn{2}{|c|}{$\begin{array}{l}+1+q \\
s p / s p d\end{array}$} & \multicolumn{2}{|c|}{$\begin{array}{l}s p / s p \text { 우 } \\
s p / s p \text { d }\end{array}$} \\
\hline & No. & Per cent. & No. & Per cent. & No. & Per cent. & No. & Per cent. \\
\hline $\begin{array}{l}\text { Fertile } \\
\text { Infertile }\end{array}$ & $\begin{array}{l}3 \mathrm{II} \\
2 \mathrm{I}\end{array}$ & $\begin{array}{l}59 \cdot 2 \\
40^{\circ} 3\end{array}$ & $\begin{array}{r}90 \\
3\end{array}$ & $\begin{array}{r}96 \cdot 7 \\
3 \cdot 2\end{array}$ & $\begin{array}{r}125 \\
9\end{array}$ & $\begin{array}{r}93.2 \\
6.7\end{array}$ & $\begin{array}{l}45 \\
16\end{array}$ & $\begin{array}{l}73 \cdot 7 \\
26 \cdot 2\end{array}$ \\
\hline Total . & \multicolumn{2}{|l|}{$5^{2}$} & \multicolumn{2}{|l|}{93} & \multicolumn{2}{|l|}{ I 34} & \multicolumn{2}{|l|}{$6 I$} \\
\hline \multicolumn{5}{|c|}{ Matings compared } & \multicolumn{2}{|r|}{$\chi^{2}$} & \multicolumn{2}{|r|}{$\mathbf{P}$} \\
\hline \multicolumn{2}{|c|}{$\begin{array}{l}+1+q \\
+1+0\end{array}$} & & \multicolumn{2}{|c|}{$\begin{array}{l}+1+q \\
s p / s p d\end{array}$} & \multicolumn{2}{|r|}{$0 \cdot 73$} & \multicolumn{2}{|r|}{0.40} \\
\hline \multicolumn{2}{|c|}{$\begin{array}{l}s p / s p q \\
+1+o^{*}\end{array}$} & & \multicolumn{2}{|c|}{$\begin{array}{l}s p / s p \text { 영 } \\
s p / s p \text { के }\end{array}$} & \multicolumn{2}{|r|}{ I.94 } & \multicolumn{2}{|r|}{0.15} \\
\hline \multicolumn{2}{|c|}{$\begin{array}{l}+1+q \\
s p / s p d\end{array}$} & & \multicolumn{2}{|c|}{$\begin{array}{l}s p / s p q \\
s p / s p d\end{array}$} & \multicolumn{2}{|c|}{$12 \cdot 59$} & \multicolumn{2}{|c|}{$<0.01$} \\
\hline \multicolumn{2}{|c|}{$\begin{array}{l}s p / s p \text { 우 } \\
+1+0^{*}\end{array}$} & & \multicolumn{2}{|c|}{$\begin{array}{l}+1+0 \\
+1+0\end{array}$} & \multicolumn{2}{|c|}{$30 \cdot 64$} & \multicolumn{2}{|c|}{$<0.01$} \\
\hline
\end{tabular}

TABLE 4

Productivity of the four different crosses where the only pairs considered were fertile during the first period and lived through the three periods

\begin{tabular}{|c|c|c|c|c|}
\hline $\begin{array}{c}\text { Pair's } \\
\text { genotypes }\end{array}$ & $\begin{array}{l}\text { No. of } \\
\text { pairs }\end{array}$ & $\begin{array}{l}\text { Total offspring } \\
\text { from last } \\
\text { two periods }\end{array}$ & $\begin{array}{l}\text { Offspring } \\
\text { per pair }\end{array}$ & $\begin{array}{l}\text { Offspring } \\
\text { per pair } \\
\text { per day }\end{array}$ \\
\hline $\begin{array}{l}+1+0 \\
+1+0\end{array}$ & 82 & $53^{8} 5$ & $65 \cdot 7$ & $6 \cdot 57$ \\
\hline $\begin{array}{l}s p / s p \text { 우 } \\
+1+0\end{array}$ & 7 & 83 & II 99 & $1 \cdot 19$ \\
\hline $\begin{array}{l}+1+q \\
s p / s p \text { o }\end{array}$ & $9^{2}$ & 4704 & $50 \cdot 9$ & 5.09 \\
\hline $\begin{array}{l}s p / s p q \\
s p / s p \sigma^{*}\end{array}$ & 25 & 6 I6 & $24 \cdot 6$ & $2 \cdot 46$ \\
\hline
\end{tabular}


of offspring per pair. Again, the most obvious difference is between the productivity of $s p$ females and wild females, but there are other interesting aspects of this data which will be discussed below.

\section{(iii) Mating experiments}

Since the $s p$ females were frequently found to be sterile and, even when fertile, less productive than wild type females, the question arose whether there might be differences in their mating behaviours as well. Pairs of mutant and wild type males and females in all possible combinations were observed by using the constant temperature box already described. Since adults frequently will not mate until

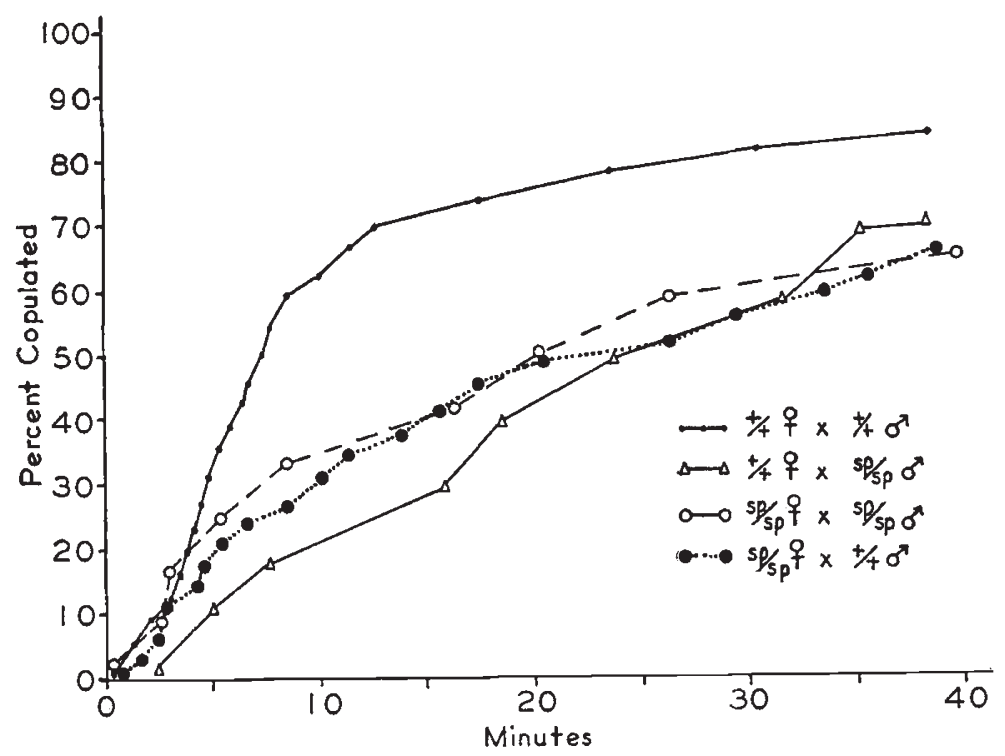

Fig. 2.-The percentage of pairs which have copulated at various intervals of time. Only the initial and final points, and approximately every fifth point between have been plotted in all curves.

three to four days old, all the insects used here were between eight and thirteen days of age. The results of the copulation experiments are presented in fig. 2 where the per cent. copulated are plotted against time. These curves demonstrate that the wild type pairs copulate much sooner than mutant pairs or either combination of mutant and wild type. Fifty per cent. of the wild type pairs have copulated within eight minutes following the introduction of the male into the dish as compared to twenty-seven minutes for $5^{\circ}$ per cent. copulation of the $+1+q \times s p / s p$ ot pairs and about twenty-one minutes for pairs involving $s p$ females with either kind of male. The data are summarised in table 5 where the mean copulation times as well as comparisons of means and variances will be found. 


\section{DISCUSSION}

It is clear from the results presented in fig. I that in the experimental populations the $s p$ frequency diminishes with considerable rapidity. Since Tribolium confusum requires about four weeks (at $30^{\circ} \mathrm{C}$.) to develop from egg to adult, a first generation was emerging between the fifth and eighth weeks, and both first and second generation individuals following the eighth week. By the tenth week, therefore, the populations were only entering the second generation, yet at this time, the frequency of $s p$ individuals had decreased from 99 to approximately 25 per cent. The equilibrium frequency of $s p$ individuals

TABLE 5

The time required for each of the four different crosses to achieve the first copulation.

Bartlett's test was applied in the variance comparisons

\begin{tabular}{|c|c|c|c|c|c|}
\hline Type & $\begin{array}{l}\text { Pair's } \\
\text { genotype }\end{array}$ & $\begin{array}{c}\text { Total } \\
\text { number } \\
\text { copulated }\end{array}$ & $\begin{array}{l}\text { Mean time } \\
\text { to first } \\
\text { copulation } \\
\text { (minutes) }\end{array}$ & $\begin{array}{l}\text { Comparison of } \\
\text { variances }\end{array}$ & $\begin{array}{l}\text { Comparison of } \\
\text { means }\end{array}$ \\
\hline I & $\begin{array}{l}+1+9 \\
+1+0\end{array}$ & 107 & $\begin{array}{l}8 \cdot 59 \pm 0 \cdot 74 \\
\text { var. }=5^{8}\end{array}$ & \multirow{2}{*}{$\begin{array}{c}\text { Types } 1,2,3 \text { and } 4 \\
x^{2}=14.77 \\
\mathrm{P}<0.01 \\
\text { heterogeneous }\end{array}$} & \multirow{2}{*}{$\begin{array}{c}\text { Types } \mathrm{I} \text { and } 4 \\
t=2.73 \\
\mathrm{P}<0.0 \mathrm{I}\end{array}$} \\
\hline 2 & $\begin{array}{l}s p / s p q \\
+1+d\end{array}$ & 95 & $\begin{array}{l}\mathrm{I} 4 \cdot 28 \pm \mathrm{I} \cdot 17 \\
\text { var. }=\mathrm{I} 3 \mathrm{I}\end{array}$ & & \\
\hline 2 & $\begin{array}{l}+1+q \\
s p / s p \sigma^{+}\end{array}$ & 35 & $\begin{array}{l}19 \cdot 50 \pm \mathrm{I} \cdot 79 \\
\text { var. }=\text { I } 33\end{array}$ & \multirow{2}{*}{$\begin{array}{c}\text { Types } 2,3 \text { and } 4 \\
\chi^{2}=0.30 \\
P=0.95 \\
\text { homogeneous }\end{array}$} & \multirow{2}{*}{$\begin{array}{c}\text { Types } 2,3 \text { and } 4 \\
F=4.08 \\
P<0.025\end{array}$} \\
\hline 4 & $\begin{array}{l}s p / s p q \\
s p / s p \text { o }\end{array}$ & 39 & $\begin{array}{l}\text { I2.42 } 12 \cdot 72 \\
\text { var. }=\text { II } 5\end{array}$ & & \\
\hline
\end{tabular}

in the absence of selection would have been about 98 per cent. Obviously, the fitness of the mutant strain must be far below that of the wild type strain under the conditions provided here; and, since the relative fitness of two phenotypes must ultimately be expressed as differences in their net reproductive capacities, the census data were examined for evidence of such disparity.

The information contained in fig. I indicates that at the tenth week the total adult population was of the order of only 2000 individuals. This is far fewer than had been found in other Tribolium population cages (McDonald and Peer, I960) where 8000 to Io,000 adults was not an unusual number at ten weeks when the populations had attained a maximum size. Furthermore, the abundance of pupae found in the weekly sample-about I 50 to I 90 per compartment for cages 20 and $2 \mathrm{I}$ respectively -indicated an expanding population, and, indeed, the adult numbers continued to increase up to the termination of the census. The reproductive capacity of the original population, which consisted almost entirely of $s p$ insects, seems, therefore, to have 
been severely limited resulting in a delayed population expansion. The nature of this limitation is explored in some detail below.

The results of the productivity experiments indicated that the $s p$ females were primarily responsible for the lower productivity of the mutant strain. Disregarding the differences among males, the data in table I show that from $248 s p$ females only I 733 offspring were obtained, or about 7.0 offspring per female; whereas the comparable figure for wild type females is $6 \mathrm{I} \cdot 6$, roughly nine times the value for mutant females. The same calculation made for males shows them to be equal in productivity, but this is misleading for it obscures the curious differences in their productivities which are dependent to a large extent upon the type of female involved.

What follows here is an attempt to resolve productivity into its components-viability, fecundity and potency-and to assess the relative importance of these components in determining the productivity and hence the relative fitness of mutant and wild type strains.

The number of offspring produced by an insect such as $T$. confusum is subject to biological limitations imposed by the organism itself. Any particular female if provided with an adequate male will prove to be fertile or infertile; and the proportion of these two kinds of females will influence productivity of the strain. The causes of infertility are: (a) death-the individual dies before it can reproduce; (b) infecundity - it lives but produces no gametes; (c) impotenceit lives and is fecund, but is unable to copulate; $(d)$ preadult inviability-offspring are produced, but die before reaching maturity. When the female proves to be fertile, productivity will be further influenced by: (a) longevity-the length of reproductive life; $(b)$ fecundity-the number of eggs produced; $(c)$ potency-the onset, frequency and success of copulatory activity; $(d)$ preadult viabilitythe number of offspring reaching maturity. Productivity will also be dependent upon environmental factors such as food supply and cannibalism, but these have not been considered here.

It is apparent from table I that a large proportion of the mutant females are sterile, for of the 248 pairs involving $s p$ females, only i 24 (50 per cent.) produced offspring; whereas $218(89.7$ per cent.) of 243 wild type females were productive $\left(\chi^{2}=89.7 ; \quad \mathrm{P}<0.001\right)$. Among the males there seems to be little if any real difference of this nature since 74.5 per cent. of the $s p$ males and 65.1 per cent. of the wild type males were fertile $\left(\chi^{2}=4 \cdot 46 ; \mathrm{P}=0 \cdot 04\right)$.

The inviability of $s p$ females is probably one of the most important factors contributing to the high proportion of sterile matings involving them. In view of the fact that the usual life span of $T$. confusum is five to six months (Pearl, Park and Miner, 194I), the death of over half the $s p$ females (table 2) within seventeen days following eclosion is quite striking. A definite explanation for the lethal effects of $s p$ cannot be given now, but Sokoloff (1960) has described a mutation, $\mathrm{x} 2$ 
truncated elytra, of the closely related species Tribolium castaneum, where the adults possess an elytral deformity similar to split and die at an early age-usually within four weeks. He suggests that water loss resulting from the exposure of the abdomen normally covered by the elytra is responsible for this inviability. Excess evaporation could indeed be involved for $T$. castaneum, like $T$. confusum, is reared in a dry flour and yeast mixture where maintenance of water balance may be a critical problem. However, this factor per se will not provide an adequate explanation for the inviability of split females encountered here, for the $s p$ males whose elytral deformities appear equally severe showed no tendency toward early death within the fifty days they remained under observation; and, in fact, their death rate was comparable to that of normal $T$. confusum. The interesting difference in the longevity of $s p$ males and females is at the moment not understood, but the sharp rise in the death of $s p$ females which occurs between the first and second observation periods, when the females are seven to twelve days old, may indicate that many of them are unable to bear the physiological burden of egg production which usually reaches a maximum rate about this time. The egg, of course, contains a considerable quantity of water, so that the onset of egg laying activity may upset the water balance of the females and result in death.

Inviability cannot be the only reason for the sterility of mutant females for the data presented in table 3 clearly indicate a difference in the proportions of fertile and infertile individuals found among $s p$ and wild females even where both types live equal lengths of time. Of the I I 3 pairs in this group containing sp females, 32.7 per cent. were sterile compared to $4^{\circ} \mathrm{o}$ per cent. infertile pairs involving wild females; and, as mentioned previously, this difference again seems to be confined to the females only.

A viable female may still be sterile if she produces no eggs or, in other words, is infecund. The question of fecundity was explored by counting the eggs found in dissected mature females removed from mass cultures containing males. The presence of males must be considered for the fecundity of Tribolium females has been shown to increase markedly if they are permitted to copulate (Park, I933) and, of course, there were males in both the cage populations and the fertility experiments.

Twenty-one females each of the mutant and wild type strains were dissected and examined under magnification. Only two of the $s p$ females contained no recognisable eggs, and the remainder had from one to six eggs each in various stages of development, with a mean number of 3.5 per female. Infecundity, therefore, probably accounts for at least some of the sterile individuals found among $s p$ females. None of the wild type females was without eggs and they contained from one to eighteen eggs, with a mean of 7.5 per female. This is roughly comparable to the figure found by Dick (1937) of five to 
eight mature eggs per female and a variable number in different developmental stages. The mean egg numbers for the two types of females are significantly different $(t=4.69 ; \mathrm{P}<0.00 \mathrm{I})$.

Another cause of the high proportion of sterile $s p$ females may be the interference of the elytral deformity with mating activities. When copulating the male must position itself on the female's back, and if copulation with $s p$ females is more difficult or impossible, pairs involving them would more frequently prove to be sterile. This hypothesis led to the copulation experiments where by observing the insects in copula the effects of the split elytra might be detectable.

The time required to achieve copulation was measured in an endeavour to quantify mating performance. The data of several experiments when pooled yield "copulation rates" whose magnitudes can be readily compared by reference to the curves in fig. 2 . It should first be noted that since the $s p$ female curves seem to be approaching asymptotes of approximately 70 per cent., about 30 per cent. of the $s p$ females may be impotent and will never copulate at all. On the other hand, while the $+1+q x+1+o^{*}$ curve substantiates the finding of little infertility in these crosses (table 3 ), the $+1+q \times$ $s p / s p$ o curve suggests a greater percentage of infertility than was actually found. However, the latter curve seems still to be in an ascending phase and might shortly have reached a much higher level. Obviously, these conclusions, while helpful, remain tentative until the experiments are extended over a longer period of time.

In addition to the difference in proportion of fertile and sterile $s p$ and wild females there is, even when they are fertile, an inequality in their productivity. The I $24 s p$ females that were fertile produced I 733 offspring or about fourteen per female as compared to the productivity of the 234 wild females who produced I4,979 offspring or $6 \mathrm{I} \cdot 6$ per female. If the fecundity of $s p$ females is only about 47 per cent. that of wild females, the $s p$ females might have been expected to produce 29 offspring per female; but since they actually produce only about half this expected value, it is necessary to seek causes other than subfecundity for the reduction in productivity.

One such cause is suggested from the fact that the death rate among fertile $s p$ females is greater than among fertile wild females. This means that many of the $s p$ females die before the fifteen day period is over and can no longer contribute offspring. This factor considered along with their subfecundity and the preadult inviability of $s p$ offspring will almost account for the lower productivity of $s p$ females. The data in table 4 show that where fertile $s p$ and wild females have both lived through the three periods and were fertile at the start of this time, wild females produced $5^{8}$ offspring per female during the last two periods as compared to $2 \mathrm{I} \cdot 8$ per $s p$ female. However, the number of offspring produced by the $s p / s p \quad q \times+1+\hat{o}$ crosses adjusted to account for the 47 per cent. fecundity of $s p$ females would be about I 77 ; and the total offspring from the $s p / s p+Q \times s p / s p o$ crosses adjusted 
for both fecundity and the preadult viability of mutant offspring of 88 per cent. would be 1489 . Thus, if the effects of longevity, fecundity, and preadult viability were eliminated, the thirty-two fertile $s p$ females would be expected to produce 1666 offspring or about 52 per female, which is close to but still slightly below productivity of the wild female. However, in view of the variability of the characteristics being measured this may be as good an agreement as can be expected.

Turning now to a comparison of the males, no great differences in life span (table 2) or in proportion of fertile matings (table I) can be found, so that the productivity differences between the males cannot be attributed to these factors. For this reason, in table 4 where only fertile and equally viable individuals are compared, a pattern of productivity emerges which is similar to that found before these factors were eliminated. Furthermore, the differences in productivity of $s p$ and wild males when mated with wild females is still significant $(t=6 . \mathrm{I} ; \mathrm{P}<0.00 \mathrm{I})$ in spite of eliminating from consideration in table 4 a large number of $s p$ males which were late in inseminating their females. Of the 127 fertile $+1+q \times s p / s p \quad \hat{\sigma}$ crosses, three were excluded because either the male or female died, and thirty-two (25. I per cent.) because they were not productive until after the first period. Only nine ( 9.9 per cent.) of the 91 fertile $+1+q x+1+\sigma$ crosses were excluded because of delayed productivity, and the proportions of delayed and immediately productive crosses in this group is significantly different $\left(\chi^{2}=7.6 \mathrm{I} ; \mathrm{P}=0.007\right)$ from these same proportions in the sp male group.

The possibility that the males are not equally precocious-at least when mated with wild type females-is further supported by the results of the copulation experiments (fig. 2), for the copulation rates of $s p$ and wild males mated with wild females are clearly seen to be dissimilar. $S p$ males, therefore, seem less adept at inseminating wild type females and, while this may be a partial explanation of the productivity differences between the males, it cannot account for the difference remaining in the data of table 4 . It is conceivable that $s p$ males are less fecund, or do not copulate as effectively (i.e., do not transfer a sufficient supply of sperm) or as frequently as wild type males. However, these possible inadequacies would still fail to account for the apparent reversal of the productivity differential between males when mated with mutant females. These productivities (table I) are significantly different, and in table 4 the pattern is the same although the significance is lost with the reduction in the number of pairs available for comparison.

The differences found thus far are still not sufficient to explain the precipitous drop in the frequency of $s p$ in the population cages, for if the males are assumed to be equally productive and the productivity of the $s p$ female is about one-sixth that of the wild female, the first generation should have been about 90 per cent. $s p$ homozygotes and a second generation produced by them over 75 per cent. sp. 
The populations at the first sampling are a mixture of first and second generations, but since the frequency of $s p$ individuals is far less than 75 per cent., the depression of the productivity of the $s p$ mutants apparently is augmented by the cage environment. One possible explanation may be that viabilities of mutant and wild type insects are differentially affected by the density of organisms in the cages. The number of adults and immature forms per gm. of medium is undoubtedly greater in the cages than in the vials used for the productivity experiments. There were only two adults per three grams of medium in each vial whereas in the population cages, by the tenth week, about 2000 adults occupied 400 gms. of medium, a density seven times that of the vials. Furthermore, for several weeks the average number of pupae in each cage was about 1500 indicating the presence of three times that many larvae. This is about eleven larvae per gm., which is four to five times greater than the density of larval offspring in vials of $s p$ female crosses. Thus, the appreciably greater cage densities may have been partly responsible for the rapid decline of $s p$ in the population. This problem and a further investigation of male productivities will be the subject of future experiments.

Finally, it is interesting to consider further the causes of the copulation rate differences found among males as well as females. Attention has already been drawn to the possibility that the elytral deformity of the $s p$ female presents an obstacle to copulation. If it is assumed that both types of males have equal difficulty in overcoming this obstacle and that the wild female presents a different obstacle which is more easily overcome by wild type than by $s p$ males, the results of the copulation experiments become meaningful. Unfortunately, observations of the mating behaviour of mutant and wild males with wild type females have produced no definite evidence of the existence of such an obstacle. Mating in $T$. confusum is devoid of the elaborate courtship rituals commonly found in other insects such as Drosophila (Spieth, 1952). The male upon encountering a female will sometimes trail after her and when she stops moving he may then attempt to mount. His efforts do not bring about any noticeable diminution of the female's activities which, in fact, may frequently lead to his being dislodged. This is the only finding which seems suggestive, for if wild type females are more vigorous than $s p$ females, their movements may be more violent and apt to dislodge more easily a weak or unbalanced $s p$ male.

The significantly larger variances in mean copulation time (table 5) obtained when one member of the pair is a mutant compared to the situation when both members are wild type should be noted, for if copulation is subject to interference by the effects of the split mutation, variation in these effects could lead to wide variation in the copulatory performance of mutant individuals. At present, all that can be said in regard to this is that the most obvious phenotypic effect of $s p$, the elytral abnormality, is highly variable in expression. 


\section{SUMMARY}

I. In experimental populations of Tribolium confusum, reared in population cages, the mutation split $(s p)$ is rapidly replaced by the normal allele, indicating that the fitness of the mutant is far below that of the wild type.

2. Responsibility for this lowered fitness of the mutant strain is not shared equally by both sexes. The productivity of mutant females is about one-sixth that of the wild type females, whereas the two types of males do not differ greatly in this respect. However, each type of male is relatively more productive with its own type of female.

3. The lower productivity of $s p$ females can be traced to their inviability, subfecundity and impotence. The reasons for the male productivity differences are not clear. However, it has been found that mutant males copulate less readily and less effectively with wild type females than do wild type males, while with mutant females neither male is more effective.

4. Estimates of the $s p$ frequencies expected in the experimental populations by the second generation are higher than the actual frequencies found. Possibly the greater densities of living organisms found in the cages adversely affect the mutants and intensify selection against them.

Acknowledgments.-The authors are grateful to Mrs Cynthia Wear and Miss Irene Tar for their valuable assistance.

\section{REFERENCES}

DICK, J. I937. Oviposition in certain Coleoptera. Ann. Appl. Biol., 24, 762-796.

HARLAND, S. C., AND JACKSON, A. R. H. 1958. Advantage of the white eye mutant of Drosophila melanogaster over the wild type in an artificial environment. Heredity, 12, 27-36.

McDonald, D. J. 1959. Two new deleterious mutations of Tribolium confusum. 7. Heredity, 50, 85-88.

MCDONALD, D. J., AND PEER, N. J. 196o. Natural selection in experimental populations of Tribolium. I. Preliminary experiments with population cages. Genetics, 45. 131 7-1 333 .

MERRELL, D. J., AND UNDERHILl, J. C. 1956. Competition between mutants in experimental populations of Drosophila melanogaster. Genetics, 4I, 469-485.

PARK, T. 1933. Studies in population physiology. II. Factors regulating the initial growth of Tribolium confusum populations. Four. Exper. Zool., 65, i 7-42.

PEARL, R., PARK, T., AND MINER, J. R. 1941. Experimental studies on the duration of life. XVI. Life tables for the flour beetle Tribolium confusum Duval. Amer. Naturalist, 75, 5-19.

PHILLIPS, A. L., AND MCDONALD, D. J. 1958. A comparison of productivity in a mutant and wild strain of Tribolium castaneum Herbst. Amer. Naturalist, 92, 376-378.

soкоloff, A. 1960. Linkage studies in Tribolium castaneum Herbst. III. A preliminary report on "truncated elytra," a sex-linked recessive gene with lethal effects. Can. 7. Genet. Cytol., 2, 379-388.

SPIEss, E. в. 1958. Chromosomal adaptive polymorphism in Drosophila persimilis. II. Effects of population cage conditions on life cycle components. Evolution, I2, 234-245.

SPIETH, H. 1949. Sexual behavior and isolation in Drosophila. II. The interspecific mating behavior of species of the willistoni group. Evolution, 3, 67-81.

SPOFFORD, J. в. 1956. The relation between expressivity and selection against eyeless in Drosophila melanogaster. Genetics, 4 I, 938-959. 